\title{
ENSINO DE MATEMÁTICA NA EDUCAÇÃO INFANTIL: RELATO DO PLANEJAMENTO DE UMA DISCIPLINA NO CONTEXTO DA EDUCAÇÃO À DISTÂNCIA.
}

LONDRINA/PR MAIO/2018

\author{
Diego Fogaça Carvalho - UNOPAR - diego.fogaca@kroton.com.br \\ Alessandra Negrini Dalla Barba - UNOPAR - alessandra.barba@kroton.com.br \\ Keila Tatiana Boni - UNOPAR - keila.boni@unopar.br \\ Sara Pimenta Lima - SEED - sarapmnt@gmail.com \\ Lilian Amaral da Silva Souza - UNOPAR - lilian.ssouza@unopar.br
}

Tipo: Relato de Experiência Inovadora (EI)

Categoria: Conteúdos e Habilidades

Setor Educacional: EDUCAÇÃO SUPERIOR

\section{RESUMO}

Neste relato de experiência tem-se por objetivo apresentar a disciplina Ensino de Matemática na Educação Infantil, na modalidade EAD, ministrada no $5^{\circ}$ semestre do curso de Licenciatura em Pedagogia, desde seu planejamento até a realização das atividades práticas, contempladas nas aulas atividades e participação nos fóruns. Compreende-se que além da abordagem teórica dos conceitos, os professores procuraram contemplar a prática, promovendo reflexões antes, durante e após as aulas, bem como fomentam a necessidade de que o docente deve adaptar e produzir as tarefas que utiliza em sua prática, tendo como critério as contingências da sala de aula.

Palavras-chave: Educação Matemática; Ensino de Matemática na Educação Infantil; Formação Matemática do Pedagogo.

\section{AGRADECIMENTOS}

AGRADECEMOS A TODOS OS PROFESSORES, TUTORES E ESTUDANTES DO CURSO DE PEDAGOGIA DA UNIVERSIDADE PITÁGORAS UNOPAR. 


\section{Introdução}

Há mais de três anos aceitamos o desafio de ministrar uma disciplina sobre o ensino da Matemática na Educação Infantil, para futuros pedagogos, na modalidade à distância, pela Universidade Pitágoras UNOPAR. Em um primeiro momento, sentimos insegurança, embora somos especialistas, mestres e doutores na área da Educação Matemática, o ensino de Matemática, no âmbito da Educação Infantil, é uma subárea muito específica, com conceitos próprios, mais próximos da área da Educação. Todavia, o incômodo se tornou motivação, possibilitando uma rotina de estudos e um leque de escolhas a serem realizadas durante o planejamento da disciplina.

A maior dificuldade que encontramos foi estabelecer um equilíbrio entre uma sólida fundamentação teórica sobre o processo de ensino e aprendizagem da Matemática e a prática docente. Tivemos por intuito não resumir a disciplina à exposição dos conceitos teóricos, mas também analisar criticamente possibilidades para a sala de aula, exemplificando tarefas que poderiam ser adaptadas pelos estudantes e utilizadas na realização dos estágios e prática em sala de aula. Por outro lado, também tivemos que elaborar uma forma de apresentar os conceitos matemáticos, pensando na formação matemática do futuro pedagogo, situada no contexto da Educação Infantil, introduzindo as tendências provenientes da área de Educação Matemática, como, por exemplo, a Resolução de Problemas, a Modelagem Matemática e a Etnomatemática.

$\mathrm{Na}$ continuidade, apresentamos nossas escolhas, elas são anualmente retomadas e analisadas à luz dos feedbacks apresentado pelos estudantes, tutores e coordenação do curso de Pedagogia, bem como as pesquisas que anualmente são produzidas. Iniciamos por alguns apontamentos que caracterizam o papel da Matemática no âmbito da Educação Infantil.

\section{O papel da matemática na Educação Infantil}

A Educação Infantil consiste na primeira etapa da educação formal, direcionada, às crianças de zero a cinco anos. Dentre os saberes essenciais a serem abordados nessa etapa, podemos destacar conhecimentos relativos à Matemática. Este trabalho, conforme o Referencial Curricular Nacional para a Educação Infantil (BRASIL, 1998), visa atender às necessidades das crianças, enquanto conhecimentos essenciais à sua formação, bem como às necessidades sociais de instrumentalização, visando a convivência social.

Os conhecimentos matemáticos estão presentes no cotidiano das crianças, desde seu 
nascimento, e são imprescindíveis em situações corriqueiras, como àquelas que envolvem contagem, medições, entre outros. Assim, a organização das informações provenientes do meio é essencial para que a criança possa emprega-las, de forma adequada, na resolução de problemas, na interpretação das situações de seu cotidiano. Nesse sentido, o trabalho com a Matemática deve ter início na Educação Infantil a partir da proposição de atividades significativas e que favoreçam a construção de conceitos pelas crianças.

De acordo com a Base Nacional Comum Curricular (BRASIL, 2018), o currículo da Educação Infantil deve ser organizado a partir de cinco campos de experiências, dentre os quais podemos destacar o campo "Espaços, tempos, quantidades, relações e transformações", do qual faz parte os saberes da Matemática relativos a contagem, ordenação, relações entre quantidades, avaliação de grandezas e medidas, reconhecimento de figuras geométricas, conhecimento e reconhecimento dos numerais, entre outros. De acordo com esse documento, nessa etapa de ensino devem ser promovidas experiências que propiciem às crianças a oportunidade de observar, manipular objetos, levantar e testas hipóteses, investigar e explorar situações diversas, de modo a favorecer a construção de conceitos e a utilização destes em seu cotidiano.

Considerando a importância do conhecimento matemático para a formação das crianças, fato evidenciado pelos dois documentos citados, a organização do trabalho docente com relação a esse campo de conhecimentos deve ser pautada em uma perspectiva na qual o aluno deva assumir papel ativo frente a seu desenvolvimento, o que pode ser favorecido pela organização de propostas que propiciem experiências significativas aos educandos em relação aos conhecimentos desse campo essenciais à etapa em questão.

Dessa forma, o professor, enquanto orientador da aprendizagem dos alunos, precisa refletir e organizar propostas que visem atingir aos objetivos estabelecidos para a Matemática na Educação Infantil, conforme as orientações do Referencial Curricular Nacional para a Educação Infantil e da Base Nacional Comum Curricular, além das legislações correspondentes. Para isso, é importante que, durante sua formação, esse profissional seja estimulado a refletir sobre sua prática e buscar um aprimoramento constante em seu trabalho. Assim, na organização da disciplina de Ensino de Matemática na Educação Infantil objetivamos a construção de um ambiente propício às reflexões e discussões a respeito das habilidades e conhecimentos matemáticos direcionados à Educação Infantil bem como das potencialidades das diferentes estratégias para a construção desses conhecimentos e, principalmente, a respeito da importância do papel do professor em todo esse processo. 
Diante disso, nas próximas seções nos dedicaremos à apresentação da disciplina e sua estruturação com base nos objetivos descritos.

\section{Objetivo do relato}

Temos por objetivo neste relato apresentar como planejamos a disciplina Ensino de Matemática na Educação Infantil, na modalidade EAD, no curso de Pedagogia da Universidade Pitágoras UNOPAR, enfatizando nossas dificuldades e escolhas que realizamos durante esse processo.

\section{Procedimentos Metodológico}

O relato que comunicamos é predominantemente qualitativo no sentido de possibilitar ao leitor acesso direto aos fatos, proveniente do ambiente natural em que ocorreram, enfatizando o processo e não o produto final, valendo-se de uma análise indutiva que valoriza os significados atribuído pelos agentes envolvidos. (Bogdan; Biklen, 1994). Para isso, o relato assume a característica de ser descritivo, ou seja, os dados coletados e analisados referem-se à depoimentos, memórias e produção escrita realizadas por nós e pelos estudantes. Na sequência, descrevemos as escolhas que realizamos ao escrever o livro didático da disciplina.

\section{O Livro da Disciplina}

Comprometidos com o objetivo de proporcionar aos futuros pedagogos acesso aos conceitos teóricos necessários para a compreensão da maneira como o ensino de Matemática se configura no contexto da Educação Infantil, bem como exemplificar tarefas que poderão ser utilizadas no desenvolvimento dos estágios ou na própria prática, em sala de aula.

Optamos por associar a cada encontro síncrono (tele aula) uma unidade do livro, Barba e Carvalho (2018). Essa estrutura possibilitou que o estudante pudesse realizar uma preparação prévia, ou seja, durante a semana que antecedeu a aula, ele pode realizar o estudo da unidade e participar do fórum, apresentando suas contribuições a respeito dos temas abordados e sanando suas dúvidas.

Sobre cada uma das unidades, além da apresentação dos conceitos teóricos, fundamentados nos autores que são referenciais consolidados em âmbitos nacional e internacional, para cada tema, foi dissolvido, ao longo do texto, momentos de reflexão, nos quais o futuro pedagogo foi indagado a respeito do contexto reportado. Essa 
inserção foi realizada de modo a proporcionar ao estudante uma problematização do tópico sequente, bem como uma síntese do tópico recém estudado.

A primeira unidade tem por objetivo apresentar os principais conceitos que fundamentam a prática pedagógica do professor no contexto da Educação Infantil, iniciando-se pelo debate das principais tendências pedagógicas com o intuito que 0 futuro pedagogo possa conhecer a diversidade de formas que o conhecimento foi compreendido, bem como o papel do professor e do aluno em cada uma dessas perspectivas. Nesse sentido, procuramos destacar as influências de cada uma das tendências na organização do trabalho pedagógico, destacando: Formalista Clássica, Empírico-Ativista, Movimento da Matemática Moderna, Construtivista e Sociointeracionista. Na sequência, são consideradas três teorias da aprendizagem, proposta por Piaget, Vygotsky e Wallon, enfatizando como que a aprendizagem da Matemática pode ocorrer no contexto da Educação Infantil.

A unidade 2 contempla o estudo das maneiras como as crianças constroem o conceito de número. Em um primeiro momento é retomada a presença do número no cotidiano, enfatizando os diversos contextos de recorrência e diferentes usos associados. Após, são apresentados e exemplificados os processos mentais que antecedem a construção do conceito de número, a saber: correspondência, comparação, classificação, sequenciação, seriação, inclusão de classes e conservação. Em seguida, fundamentando-se no construtivismo piagetiano, a construção do conceito de número é caracterizada como a síntese de ordem e inclusão hierárquica construída pela criança em relação aos objetos por meio da abstração reflexiva. (KAMI; DECLARK, 1991). Finalizando a seção, são apresentadas dezoito tarefas que podem ser aplicadas e adaptadas pelos futuros professores a respeito do desenvolvimento dos processos mentais básicos, com o intuito de mostrar aos estudantes que, por mais que as atividades pareçam triviais, é de extrema importância que as crianças vivenciem essa experiência, pois o desenvolvimento desses processos não implica somente na aprendizagem da Matemática, englobando todo o desenvolvimento intelectual.

Refletir sobre a Matemática vem a ser abordada no contexto da Educação Infantil consiste no objetivo da terceira unidade. O estudo é iniciado por meio da apresentação do papel do ensino de Matemática no âmbito da Educação Infantil por meio do Referencial Curricular Nacional para Educação Infantil, bem como a Base Nacional Comum Curricular. Após, procura-se discutir como se dá a organização dos conteúdos, tempo e a avaliação sugerida pelos documentos oficiais.

O livro é finalizado com a abordagem de tendências metodológicas advindas da área da 
Educação Matemática, acenando ao futuro professor que há uma área de conhecimento formadas por pesquisadores e que visa estudar especificadamente a Matemática no contexto de ensino e aprendizagem. Além da apresentação das principais características de cada uma das tendências, procuramos apresentar exemplos de tarefas, baseando-se em diversos relatos de experiência que foram publicados em anais de eventos nos últimos anos. A primeira tendência a ser abordada foi a Resolução de Problemas, de acordo com a concepção que a caracteriza como meio de aprendizagem da Matemática. Em seguida, foi apresentada a Contação de Histórias e o uso de Jogos e Brincadeiras. Ficou claro, nesse primeiro momento, a necessidade de o professor proporcionar às crianças um ambiente de aprendizagem de Matemática no qual elas possam construir o conhecimento matemático. Na continuidade, foram apresentadas a Modelagem Matemática, na perspectiva da Educação Matemática e a Etnomatemática, ampliando as possibilidades de formas diferenciadas de como se pode ensinar Matemática no contexto da Educação Infantil.

A explanação que acabamos de realizar, enfatiza o cuidado que tivemos para contemplar os conceitos teóricos necessários para a formação do pedagogo, bem como a sua articulação com a prática por meio de exemplo de atividades baseadas em relatos de experiência e momentos de reflexão. Na sequência, descreveremos como ocorrem os momentos síncronos da disciplina, por meio da teleaulas e da mediação via chat das aulas atividades.

\section{As teleaulas e aulas atividades}

Os momentos em que são realizados os contatos síncronos com os alunos, por meio da mediação dos tutores presenciais, consistem nas teleaulas e aulas atividades. Nesses momentos, procura-se organizar propostas de estudo, bem como tarefas que propiciem aos estudantes realizar reflexões a respeito, principalmente, da importância do trabalho com a Matemática desde a Educação Infantil, buscando a valorização dos conhecimentos prévios das crianças, os quais devem ser investigados a partir de uma avaliação condizente com os objetivos propostos para a etapa em questão.

Nas teleaulas procuramos abordar os principais elementos que influenciam na organização do trabalho pedagógico com a Matemática na Educação Infantil, partindo de alguns questionamentos como, por exemplo, "como as crianças constroem o conceito de número?", "que Matemática deve ser abordada na Educação Infantil?" e "que metodologias podem ser adotadas na Educação Infantil?". Com base nesses questionamentos são explorados conceitos como os processos mentais básicos para a aprendizagem da Matemática, os conteúdos matemáticos a serem tratados na 
Educação Infantil, bem como as estratégias metodológicas condizentes com as características dessa etapa de ensino. A organização das aulas com base em questionamentos foi selecionada por auxiliar o futuro professor na identificação dos objetivos e principais temas que seriam abordados em cada momento, permitindo, inclusive, uma associação com as unidades do livro correspondente à essa disciplina.

Os estudos desenvolvidos nas teleaulas e aulas atividades são iniciados com a retomada das principais características de algumas tendências pedagógicas, como a Tendência Construtivista, e de algumas teorias de desenvolvimento, em concordância com a primeira unidade do livro e visando a construção de um referencial teórico que possa auxiliar na compreensão, dentre outros, da forma como os conceitos matemáticos são estruturados e como o conceito de número é construído pelas crianças, por se tratar de um dos principais conhecimentos da Matemática a ser abordado na Educação Infantil.

A partir desse referencial teórico, são analisadas as orientações do Referencial Curricular Nacional para a Educação Infantil e da Base Nacional Comum Curricular quanto à organização dos conteúdos, do tempo e da avaliação na etapa considerada, direcionando-os à Matemática e suas especificidades. Esse trabalho visa evidenciar a importância de abordar as noções matemáticas e os processos mentais básicos por meio de atividades significativas. É importante que o licenciando em Pedagogia observe que, na Educação Infantil, o foco é a exploração, a construção e a observação das primeiras noções matemáticas sem o incentivo à mera memorização e reprodução das informações, fato que pode ser ainda observado em instituições de Educação Infantil.

Durante as aulas atividades, em consonância com os temas abordados nas teleaulas correspondentes, são propostos estudos de artigos e a elaboração de alguns materiais voltados ao ensino da Matemática na Educação Infantil. Nos anos de 2017 e 2018 duas propostas foram desenvolvidas e consistiram na elaboração de histórias em quadrinhos, jogos e/ou materiais manipuláveis voltados à disciplina em questão.

$\mathrm{Na}$ elaboração de histórias em quadrinhos, a proposta era de que os estudantes construíssem uma história que envolvesse diretamente os conceitos matemáticos, principalmente os sete processos mentais básicos para a aprendizagem da Matemática, ou que as histórias fornecessem contextos a partir dos quais fosse possível trabalhar, principalmente, com esses processos. No segundo caso, em conjunto com a história, os alunos elaboraram atividades que propiciassem o desenvolvimento de processos mentais básicos a partir de materiais diferenciados. 
Na sequência exemplificamos uma das atividades realizadas por um grupo de estudantes. Na foto 01 apresentamos duas atividades realizadas pelos estudantes, onde a primeira evidencia o processo de seriação e a segunda, a sequenciação.

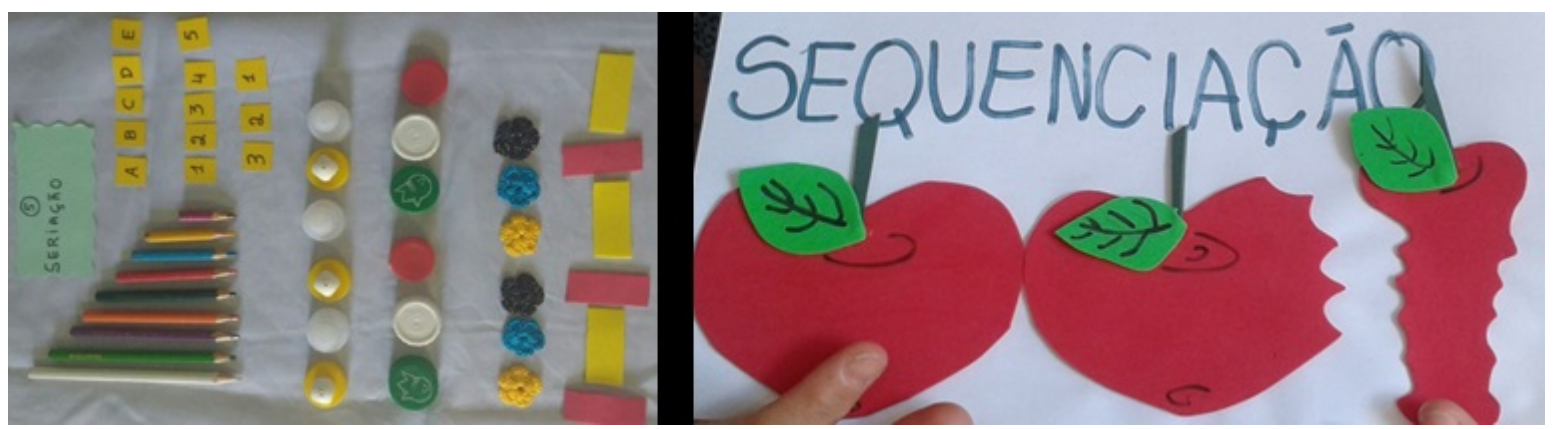

Foto 01 - Atividades elaborada pelos futuros professores durante a disciplina

Na segunda proposta - a elaboração de jogos e/ou materiais manipuláveis -, os alunos deveriam refletir sobre os conteúdos matemáticos direcionados à Educação Infantil, com base nas orientações do Referencial Curricular Nacional para a Educação Infantil e de materiais complementares. Os jogos poderiam ser construídos para crianças de qualquer idade, considerando a faixa característica da Educação Infantil (0 a 5 anos). Porém, para cada tarefa seria necessário estabelecer objetivos, manifestando assim uma intencionalidade pedagógica com o desenvolvimento dessas atividades lúdicas.

$\mathrm{Na}$ foto 02 apresentamos dois jogos elaborados pelos grupos de estudantes, o primerio do tipo dominó, utilizado para o desenvolvimento do processo de comparação, e quebracabeça, cujo objetivo seria o reconhecimento e identificação dos números de 1 a 10 , exigindo das crianças o emprego da contagem, envolvendo a correspondência, a comparação, entre outros processos.

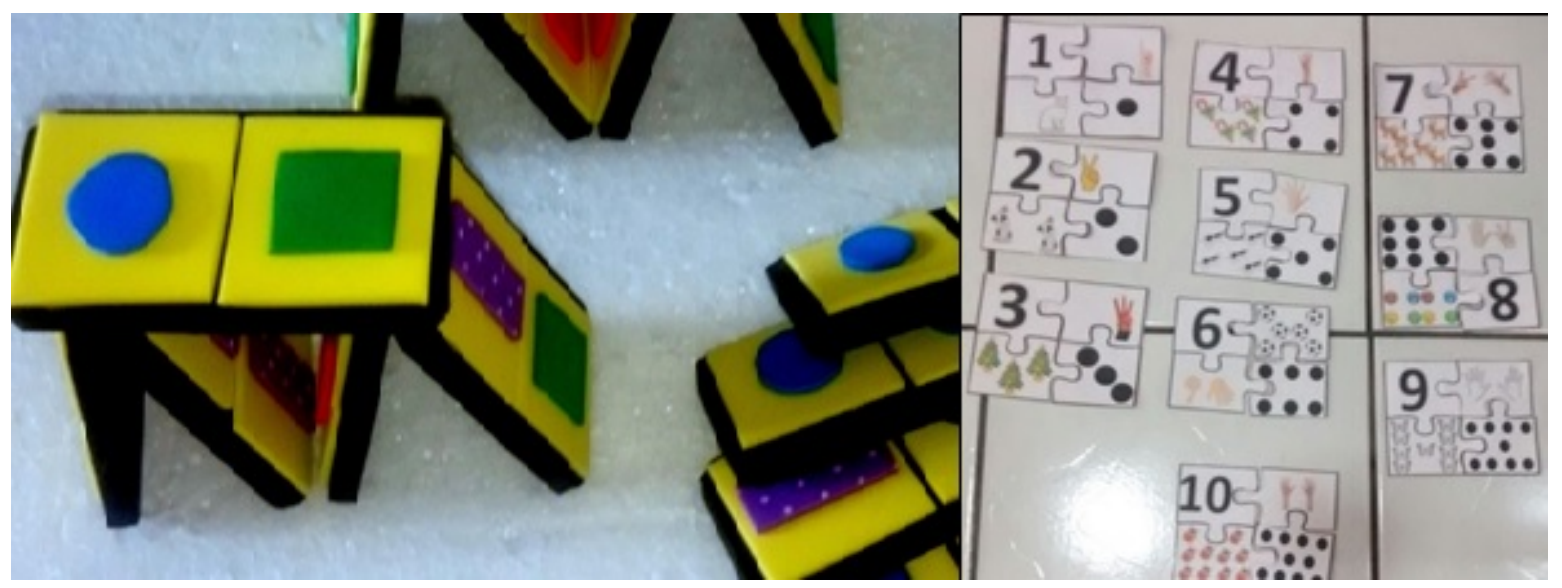

Foto 02 - Jogo elaborado pelos futuros professores durante a disciplina 
Além dos momentos descritos, os estudantes podem continuar a discussão dos conteúdos e sanar suas dúvidas por meio do fórum, que corresponde a uma ferramenta assíncrona, mediada pelos professores e tutores, e que possibilita uma interação constante com os estudantes e a proposição de outros temas para reflexão, complementando os estudos realizados nas aulas, aulas atividades e pelo livro da disciplina. Na sequência, tecemos algumas considerações, evidenciado os elementos que compreendemos caracterizar por inovação a forma como planejamos e realizamos as atividades descritas anteriormente.

\section{Considerações Finais}

A abordagem da Matemática na formação do licenciando em Pedagogia é estruturante, pois se refere a um dos principais campos do conhecimento com que esse profissional trabalhará em sua atuação profissional. Além dos conhecimentos matemáticos, é importante refletir sobre a forma como abordá-los com as crianças, em concordância com os objetivos estabelecidos para a Educação Infantil.

Assim, o planejamento da disciplina é caracterizado por uma prática inovadora, por configurar espaços de reflexão a respeito da importância da Matemática para a Educação Infantil e sobre o papel do professor nesse processo, possibilitando a elaboração de atividades práticas, fundamentadas nos conceitos teóricos e nas perspectivas dos estudantes a respeito de como se dá a aprendizagem do aluno nesse contexto de ensino. Após a finalização das atividades, o futuro pedagogo foi convidado a desenvolver processos de auto avaliação, por meio de contínuas reflexões a respeito das práticas realizadas no ambiente virtual, por meio dos fóruns temáticos. Em suma, compreendemos que a formação matemática do pedagogo se dá na em um processo cíclico, em que os estudos dos conceitos teóricos, bem como a reflexão da prática simulada, devem sempre ser retomados de modo que um possa refinar o outro, na busca de um equilíbrio de modo a proporcionar que o sujeito se desenvolva profissionalmente.

\section{Referências:}

BARBA, A. N. D.; CARVALHO, D. F. Ensino de matemática na educação infantil. Londrina: Editora e Distribuidora Educacional S.A., 2018.

BOGDAN, R. C.; BIKLEN, S. K. Investigação qualitativa em educação. Trad. Maria J. Alvez, Sara B. dos Santos e Telmo M. Baptista. Porto: Porto Editora, 1994. 
BRASIL. Base Nacional Comum Curricular (BNCC). Brasília, MEC/CONSED/UNDIME, 2018. Disponível em: . Acesso em: 19 maio 2018.

— Secretaria de Educação Fundamental. Coordenação Geral de Educação Infantil. ReferencialCurricularNacionalparaaEducaçãoInfantil. Brasília, DF: MEC/SEF/COEDI, 1998.

KAMII, C.; DECLARK. Reinventando a aritmética: implicações da teoria de Piaget. Tra. Elenisa Curt, Marina Célia M. Dias e Maria do Carmo D. Mendonça. Campinas, SP: Papirus, 1991. 